Arhe XVII, 34/2020

UDK 164

DOI https://doi.org/10.19090/arhe.2020.34.61-83

Originalni naučni rad

Original Scientific Article

\author{
KATARINA MAKSIMOVIĆ ${ }^{1}$ \\ University of Belgrade, Faculty of Philosophy
}

\title{
FACETS OF INTENSIONALITY
}

\begin{abstract}
The goal of this paper is to introduce the reader to the distinction between intensional and extensional as a distinction between different approaches to meaning. We will argue that despite the common belief, intensional aspects of mathematical notions can be, and in fact have been successfully described in mathematics. One that is for us particularly interesting is the notion of deduction as depicted in general proof theory. Our considerations result in defending a) the importance of a rule-based semantical approach and b) the position according to which non-reductive and somewhat circular explanations play an essential role in describing intensionality in mathematics.
\end{abstract}

Keywords: intensional logic, intensional definition, proof-theoretic semantics, proof theory, implicit definitions

\section{INTRODUCTION}

The demarcation between intensional and extensional is closely related to a distinction rooted in Frege's philosophy of language. According to Frege, the meaning of a word or a linguistic segment has two components. When one is interested in questions such as What does $P$ stand for, Which objects does $P$ designate, Which objects does $P$ refer to, one is asking about the reference (Bedeutung) of a linguistic expression P. But, when inquiring about the content that $\mathrm{P}$ expresses, about the rules or properties in virtue of which $\mathrm{P}$ picks out an object, one

\footnotetext{
${ }^{1}$ Author's e-mail address: katamax21@gmail.com
} 
is asking about the sense (Sinn) of P. In Frege's philosophy of language sense and reference represent the two aspects of meaning.

Given these two different aspects, one can accordingly distinguish two approaches in conceptual analysis or in any kind of semantical considerations. The first approach is centered on the reference of linguistic expressions, and it has long been dominant in logic, and in mathematics in general. Such an approach will be called extensional. According to the extensional approach, words behave like labels. Their meaning consists exclusively in signifying objects. ${ }^{2}$ On the other hand, an intensional approach takes into consideration the sense of linguistic expressions. Such an approach was mostly neglected in logic, modern mathematics and even, to a certain extent, in the philosophy of language. However, we will argue that despite the common belief, intensional aspects of mathematical notions can be, and in fact have been successfully described in mathematics. One of these notions is the notion of deduction depicted in general proof theory. The more general goal of this paper is to introduce the reader to the distinction between intensional and extensional as a distinction between different approaches to meaning especially in regards to notions in logic and mathematics.

\section{THE EXTENSIONAL REVOLUTION}

As already mentioned, in Frege's philosophy meaning has two components: sense and reference. Distinguishing between sense and reference becomes significant when one realizes that the two do not always correlate. Some expressions have the same reference, but differ in sense, such as for instance, the morning star and the evening star. Even though both point to the same celestial object (the planet Venus), the criteria for something to be a morning star (the star that appears in the east before sunrise) are not the same as the criteria for something to be an evening star (the star that appears in the west after sunset).

\footnotetext{
${ }^{2}$ In his Philosophical investigations (Wittgenstein 1958, 2) ascribes this view to Saint Augustine based on (Augustine, Confessions I, ch. 8).
} 
According to the account depicted by Frege, the identity of reference does not imply the identity of meaning. However, in the passages that follow we wish to present a different semantical perspective, one that has stood behind some of the main ideas in logic, mathematics, and set theory. This perspective is called the extensional approach.

According to the extensional approach, all linguistic expressions possess a label-like behavior. Their meaning is reduced to the objects, or classes of objects they denote. In the semantics for classical logic not just individual constants, but predicates, propositions, as well as connectives are all understood as labels for different set-theoretic objects (individuals, sets, functions, etc.). Of course, these expressions differ syntactically, as they have different functions in building propositions. But from the perspective of semantics, their meaning is understood by the same model: a model of a label being attached to the labeled object.

In the semantics of classical propositional logic the proposition is viewed as a label for a truth value. It can mean only two things - true or false. (The truth values are also understood in a set theoretic manner. The truth value false is an empty set while the value true is a singleton.) Accordingly, propositional connectives are, from the semantical standpoint, regarded as labels for truth functions. In the semantics of classical first-order calculus, n-ary predicates are interpreted by n-ary relations, and unary predicates are interpreted by subsets of a domain of discourse.

While it can be argued that for some predicates the extensional approach is not so remote from our intuitive understanding (take for example the words for colors $)^{3}$, for a vast majority of them this is evidently not the case. It is doubtful that one would so easily accept that the meaning of the predicate smart can be reduced to the set of people (or objects) that possess this property. When inquiring about the meaning of $\mathrm{P}$ one is usually not only interested in which concrete objects are $\mathrm{P}$ but

\footnotetext{
${ }^{3}$ According to the extensional picture, the predicate blue is interpreted as a set of blue things (on a specified domain). Even though the meaning of blue is intuitively associated with the specific impression, this impression can hardly be verbalized or explained without reference to the class of blue things.
} 
also in the rules or criteria by which we pick out $\mathrm{P}$ things from the ones which are not.

The reason why the interpretation of predicates, and modeltheoretic semantics in general is extensional is primarily because the notion of set in mathematics is understood extensionally. The extensionality arises from the identity criteria for sets. In set theory, two sets are equal if and only if they have the same members. In other words, the equality of members is the necessary and the sufficient condition for the equality of sets. These identity criteria are postulated in ZF set theory by the axiom of extensionality. This axiom abstracts from a rule or a property in virtue of which one determines the membership in a set. Consider for instance the following two sets: the set of geometric images with three corners and the set of geometric images with three sides. Intuitively, the two sets are considered to be different based on set membership criteria. The expressions "having three corners" and "having three sides" represent distinct notions, they express different senses. However, under the extensional approach, one abstracts away from the intensional aspects of meaning. Since, every image with three sides will also have three corners, and vice versa, the two sets are regarded identical.

Although Frege puts it somewhat differently ${ }^{4}$, using his terminology, one can specify the reference of a unary predicate to be a set, and its sense be a concept. To avoid paradoxes, one can instead speak of classes or specify in advance the domain of discourse, as it is done in the predicate calculus. In the classical model-theoretic semantic one forgets about concepts and considers only extensions - subsets of a domain. This is not to say that by taking such an approach one necessarily believes that there are no such things as concepts, and that there is nothing more (semantically) to a unary predicate then a set. It is just that concepts as well as the rest of the intensional baggage are seen as irrelevant for the analysis in question.

\footnotetext{
${ }^{4}$ For Frege, the extension of a predicate is a value range of the function that that predicate represents. See: (Frege 1891)
} 
Just as the notion of set is extensionally defined, so is the notion of relation. According to our intuitive understanding, if $a$ and $b$ stand in a relation, then there should be a connection between $a$ and $b$ determined by a set of rules. But in mathematics, a binary relation between the sets A,B is defined as a subset of the Cartesian product of A and B - a set of ordered pairs $(a, b)$, such that $a$ is a member of $A$ and $b$ a member of $B$. Consequently, two relations between sets $\mathrm{A}$ and $\mathrm{B}$ are considered equal if they comprise the same set. The rules according to which ordered pairs are connected are considered insignificant.

Extensionalizing is a way of abstracting - we abstract from the intensional components of meaning and focus on the ones that are related to naming - reference. Abstracting is a kind of rational forgetting. This rational forgetting has enabled precision, simplicity, rigor, and led to numerous desirable properties such as the completeness of classical propositional and predicate logic, truth-functionality of the connectives and functional completeness of some of them.

An outstanding example of a successful extensional analysis in logic is the discovery of the material implication. Indeed, all the diversity and the richness of meaning tied to "if then" of ordinary language are not even remotely exhausted by the truth-functional account. They are abstracted from, forgotten. Simplicity and scarcity of this analysis, however, which stand opposed to opulence of natural language should not be considered as signs of failure, in contrast to what is generally believed in philosophy, but rather a sign of a very successful linguistic and philosophical analysis (Došen 2013, 26-27). Giving up the task of literally imitating natural language and taking a modest approach has in return resulted in numerous fruitful consequences, above all including simplicity and precision characteristic to logical rigor. Although the material implication does not capture the full meaning of if then of natural language, it captures nevertheless an essential one.

The extensional approach to mathematics has not always been the dominant view. Until the second half of the $19^{\text {th }}$ century, the aim of mathematics was understood as having to do with calculation and problem solving. A great turn in a way of thinking about mathematics was caused by what Keith Devlin called the Göttingen Revolution. 
(Devlin 2003) The revolution took place in Göttingen in the 1850s. One of the turning-points of the revolution was the transition to the extensional understanding of mathematical notions. Among these notions one is especially important and well known - the notion of function. Previously, a function was viewed as something closely connected to formulas of a specific kind, namely equations, such as: $y=2+3 x-5$. A function was also conceived as a sort of a rule or a procedure for solving such an equation, a procedure that was supposed to take us from the numbers signified by a variable ' $x$ ' called 'arguments' to the numbers signified by ' $y$ ' called 'values'. By extensionalizing the notion of function, the procedure itself became less important and all that mattered was the outcome of applying the rules - which values are assigned to which arguments. A function was thus reduced to a set of ordered pairs, the first projections of which were arguments, and the second projections were values, (arguments and values, of course, being from a specified domain and codomain respectively). That simplification turned out to be quite a convenient one. The concept of a function thus became a precisely defined, abstract mathematical concept - a set, whose properties (such as, for instance, the property of always giving different values for different arguments, that is, the property of being an injection) were objects of mathematical investigation.

Extensionalising the notion of function implied extensionalising the identity criteria for functions. Two functions on the same domain and codomain are considered equal if they represented the same sets of ordered pairs. Even though, one may utilize different procedures, different rules in order to obtain the results of applying these functions.

In (Frege 1891) Frege defines the notion of a value-range which is very similar to the extensional notion of a function as a set of ordered pairs. However, Frege does not identify the function with its value-range. For Frege a function is an unsatured entity that is defined primarily by its behavior - mapping arguments to values. The reference of functional expressions such as $2+(0 \times x)$, is not the function itself, according to Frege, but its value-range. So, the propositions such as " $2+(0 \times x)=2+$ $(\mathrm{x}-\mathrm{x})$ " expresses the identity of value-ranges of the two functions, but not the identity of the functions themselves. Frege's account appears not so 
remote from the idea that the senses of these functional expressions could in fact be procedures or sequences of rules for calculating the values for the given arguments, though it is very doubtful that these were his own views. Regarding calculable functions, it is clear that the procedures ought to be effective. But in the case of the ones that are not, it is hard to imagine what these non-effective procedures would look like. Infinite procedures as the ones described by the infinite lambda terms (Berarducci \& Dezani-Ciancaglini 1999) and infinite Turing machines (Hamkins \& Lewis 1998) might be a good candidate though.

According to the post-revolutionary conception of mathematics, mathematics is an investigation of conceptual reality - the reality of abstract mathematical objects (such as sets, functions, etc). The main aim of mathematical study is discovering truths about this conceptual world and the abstract objects existing therein. The post-revolutionary picture of mathematics is very much in the spirit of platonism and the extensional view is, if not inseparable of, than at least very closely related to it. However, in spite of the fact that many working mathematicians and philosophers of the $20^{\text {th }}$ century argued vigorously against platonism, and yet more still do, the extensional approach has been the dominant view in mathematics and logic due to its tremendous success, especially the success of set theory.

Inspired by this success, one has turned more and more to extensional explanations not just in logic but also in the philosophy of language. An example is the theory of meaning proposed by Donald Davidson (Davidson 1967) which, inspired by classical model-theoretic semantics reduces the meaning of a proposition to its truth conditions.

It seems that the extensionally oriented theories in the philosophy of language, were also motivated by a need to get around the issues of analyzing the intensional components of meaning. The biggest obstacle for an account of sense is to define clear and precise identity criteria for senses. (By identity criteria for senses we understand the necessary and sufficient conditions under which two expressions have the same sense.)

There are in general three kinds of criteria for the sameness of sense of mathematical expressions. A) One can be a deflationist, and reduce the sense to reference (in the manner of set theory). This is what 
the extensional approach does. B) On the other hand, one can define the equality of sense in terms of the identity of syntax. This view is not deflationary, but it is not particularly interesting either. The equality of senses is then rather trivialized and leaves very little to the investigation. ${ }^{5}$ In addition, one can stipulate certain terms s,t as synonymous (as for instance, 1 and $S(0)$ ), and define synonymy in a standard inductive manner. Depending on the synonymy relation, the criteria for the sameness of sense can also end up to be rather trivial. ${ }^{6}$

C) The third kind of sense identity criteria are such that the sameness of sense is defined through a non-trivial equivalence relation on the set of particular expressions, such that two expressions would stand in this relation if they have the same sense. In other words, one would define or characterize the sense of this class of expressions as an equivalence class. The non-triviality condition presumes non-reducibility to syntactical equality on one hand, and to reference, on the other. It also presumes that the equivalence relation thereby defined has some mathematical significance. The last condition is admittedly somewhat vague, but it should become clearer as we advance to the examples of such identity criteria for senses in the chapters that follow.

Each of these options, A, B or C, is perfectly fine on its own. It is only appropriate however to call the third one intensional. In the following chapter as well as in the rest of this paper, we will direct our attention to analyzing the approach $\mathrm{C}$ and inspecting particular instances of it.

${ }^{5}$ A footnote in (Gödel 1944, 130) indicates that Gödel disregards the conception of sense identity criteria based on B above. He says that one needs weaker criteria that the ones based on pure syntax, thus suggesting that the sense should be beyond syntax, or differently put, that two mathematical expression that are differently built in terms of syntax can express one and the same sense.

${ }^{6}$ This is the case, for example, if all the atomic clauses for synonymy are of the form $s=t$, where $s$ is an atomic term, not having a prior meaning and introduced and defined on the basis of $\mathrm{t}$ for economic reasons (as for instance, 1 and $S(0)$ ). 


\section{INTENSIONALITY IN LOGIC}

Opposed to the dominant view in logic and mathematic in general, Gödel argued that the notion of sense can be precisely formulated and that the intensional approach in logic would bring considerable advantages. ${ }^{7}$ Although his ideas were only but scarcely developed, it is clear that his conception of intensional logic would be something close to set theory. In this logic, instead of sets, the main object of study would be concepts. According to Gödel, this theory should be type-free and the application of concepts to objects should differ from the set membership relation because it should be possible to apply a concept to itself in a manner that cannot be done with sets due to paradoxes.

While Gödel's work on intensionality consisted more in general guidelines, Church actively worked on developing a formal apparatus for talking about denotations of terms (references) and intensions which he calls concepts (senses) (Church 1951). His primary object of consideration was the relation between a thing and the concept of which that thing is an instance. Whereas Gödel believed that the intensional logic should remain type-free, Church centered his work on the simply typed lambda calculus. Church's theory faced problems regarding consistency which lead to it being reformulated multiple times (Church, 1973 ; 1974; 1993), never really providing a definite, finished formal system of an intensional logic.

In this paper we do not intend to write about Church's theory or Gödel's ideas on intensionality in further detail nor about similar approaches. Because our objective here is not to investigate logic that makes senses in general the object of its study. The role of Gödel's and Church's endeavor for this work is mostly inspirational and heuristic. In what follows, our objective is to analyze the particular instances of the intensional approach in logic and mathematics and see how the

${ }^{7}$ Gödel's comments on intensionality are reconstructed from his published works, (Wang 1996, 247-287) and his Nachlass published in (Crocco 2017). For a more detailed exposition, the reader is referred to (Kostić, in prep.) 
intensional aspects of meaning of some particular notions, such as the notion of deduction can be captured mathematically.

Moreover, one could make a distinction between our approach and the ones taken by Gödel and Church by saying that while our approach is intensional, their approach is meta-intensional. Common to the meta-intensional approaches of Church and Gödel is their goal to represent sense and the relation between sense and reference as central. However, an intensional approach we will argue for here does not necessarily presuppose the traditional definition of sense which rests on the distinction between sense and reference. The Fregean distinction is descriptivist. It is grounded in the supposition that the main language function is to describe the world around us. There the notion of reference is central, and the notion of sense is defined in terms of reference, as a set of rules or conditions for determining reference etc. In such a world imperatives, questions and other prescriptive functions of language are somewhat forgotten. (See: Maksimović 2016)

Following the later Wittgenstein (Wittgenstein 1958) such an account can be challenged. According to this new broader view, a different notion of sense can be defined: a sense of a word (linguistic segment) $\mathrm{P}$ is grounded in the rules that determine the use of $P$. Notice that we are no more talking about the reference of $P$ but just about the way it is used in a particular language setting. (Two expressions would then have the same sense if the same rules determine their use.)

Such an approach to meaning is taken in proof theoretic semantics (PTS). (For an introduction on PTS see: Schroeder-Heister 2012) In PTS logical connectives are not understood as labels for settheoretic entities but they are defined functionally - by the rules they obey in deduction. PTS is based upon natural deduction systems as the one in (Gentzen 1935), mainly for intuitionistic logic. In these systems, every logical connective comes with a pair of introduction and elimination rules. The introduction rules for an n-ary connective * express conditions in which one is allowed to infer the proposition $* A_{1} \ldots A_{n}$. For instance, the rule for introducing conjunction states that from the two premises $\mathrm{A}, \mathrm{B}$ one infers $\mathrm{A} \wedge \mathrm{B}$. The rule for introducing disjunction states that one can infer the disjunction $A \vee B$ from either the 
premise A alone or the premise $\mathrm{B}$ alone. Elimination rules for a connective $*$, on the other hand, prescribe what can be deduced from the proposition $* A_{1} \ldots A_{n}$. So, for instance, from $A \wedge B$ one can infer $A$ or alternatively, $\mathrm{B}$. The disjunction case is somewhat more complicated but still rather intuitive. To eliminate $\mathrm{A} \vee \mathrm{B}$ one supposes $\mathrm{A}$ and $\mathrm{B}$ as independent hypotheses. If a common conclusion $\mathrm{C}$ is reached, from both $\mathrm{A}$ and $\mathrm{B}$ independently, the elimination can be finished and $\mathrm{C}$ inferred, while $\mathrm{A}$ and $\mathrm{B}$ are no longer considered as relevant and may be discharged.

In PTS the connective is defined by the introduction and elimination rules for that connective. There is a tradition, stemming from Gentzen, of commonly regarding the introduction rules as so to say definitions of the connectives, whereas the elimination rules are seen as consequences of the introduction rules. A research suggest, however, that the psychological order of acquiring these rules is inverted (Kostić, Maksimović, Milošević, in prep.). This arguably favors the proposals that the elimination rules should be taken as primary. The idea of such an interpretation is first found in (Dummet 1991, ch.13) and developed in more detail in (Prawitz 1971) (see also: Schroeder-Heister 2015).

Regardless, the relation between introduction and elimination rules is for PTS of great importance. In Gentzen's sequent calculus it is mirrored in the symmetry between left and right introduction rules and the principle that governs it is in PTS called the principle of harmony (Schroeder-Heister 2012). An explanation of such a phenomenon is related to the fact that the (intuitionistic) logical connectives are characterized by adjunctions (See: Došen 2001). Consequently, their deductive behavior and their meaning can be described in terms of double-line rules in the framework of sequent calculus (Došen 1989) (Schroeder-Heister 2013). The expression "double-line" comes from the fact that these rules can be read in both ways, from top to bottom and from bottom to top.

Interestingly, there is even some empirical evidence suggesting that a rule based interpretation of the logical connectives, as the one offered by PTS, is maybe more suited to how the meaning of these 
connectives is acquired in real life (Kostić, Maksimović, Milošević, in prep.). But none of our considerations here depend on it.

Before proof theoretic semantics, the first intensional breakthrough in logic was made by the intuitionists. The intuitionistic logic is most well-known for rejecting the law of the excluded middle (in this logic $A \vee \neg A$ is not a theorem). This is commonly interpreted as the consequence of accepting constructivism. Constructivism is a position in the philosophy of mathematics according to which mathematical objects do not exist independently of the human mind (in the way physical object do, for example). ${ }^{8}$ They are just human constructions. ${ }^{9}$ If constructivism is to be accepted, the notion of truth in mathematics must be reformulated accordingly. The validity of the propositions about mathematical objects cannot consist in the correspondence with the platonic world of mathematics, since this world does not exist. Hence, it must consist in something that is related to how we come to accept these propositions and that is directly accessible to the human mind. The answer is provability. According to this interpretation of intuitionism, asserting $A$ should not be understood as $A$ is true, but as $A$ is provable. ${ }^{10}$

By taking this point of view, one is bound to reject the law of the excluded middle. It cannot just be supposed a priori that every mathematical conjecture is either provable or that its negation is. Especially if negation is not taken as primitive but as defined by: $A$ implies absurdity, which should be very natural for the intuitionist, since truth is reduced to provability. So, under the intuitionistic reading the law of the excluded middle should be understood as: either $A$ is provable or from $A$ one can deduce absurdity. And this is not something that can be a

${ }^{8}$ See more about constructivism and how it is connected to intuitionism in (Dummett 1978), especially: 50-66, 215-248.

${ }^{9}$ This does not mean, however, that these constructions should be understood as subjective. Even though their metaphysical status is not entirely clear, it seems reasonable to suppose that their reality is on par with what Kant calls the intersubjective.

${ }^{10}$ See more about different interpretations of intuitionistic logic in (Maksimović 2016). 
priori accepted for an arbitrary $\mathrm{A}$. The axiom of choice $\mathrm{AC}^{11}$, for instance, is consistent with ZF (Zermelo-Fraenkel axiomatization of set theory), but its negation is also. Under the assumption that $\mathrm{ZF}$ is consistent, ZF does not prove AC or its negation.

However, we will offer a different account of intuitionistic logic, one that is not necessarily connected to constructivism. Following (Došen 1989), the difference between intuitionistic and classical logic can be based upon a different understanding of the logical implication. In classical logic, implication is material. It is defined truth-functionally by using negation and disjunction. Hence, the proposition if $A$, then $B$ can simply be read as not $A$ or $B$. As one might observe, offering the material conditional as an analysis of the if then of ordinary language represents quite a simplification. Evidently, through this simplification, we have lost some of the meaning including the connection between an antecedent and a consequent. It appears that in natural language this connection is mostly causal, like in If you drop a glass, it will break. In (Frege 1879, 13) Frege conjectured that such connections are not a part of the meaning of if then, but should be rather thought of as grounds for asserting the implication, which is a view close to Grice (Grice 1989).

Admittedly, in logic and mathematics in general one is not at all concerned about causal connections between events. Deductive connections between propositions are, however, fundamental. In mathematics, the questions concerning if $A$ then $B$ cannot always be settled by simply finding out the truth values of $A$ and $B$. More often, one is interested in how B can be deduced from the assumption A. In fact, deduction can be considered as an integral aspect of the meaning of if then in mathematics. This aspect of meaning, Došen argues, is the one intuitionistic implication is centered on. According to his account, the main difference between an intuitionist and a classical logician is that while in classical logic the implication is understood truth-functionally, the intuitionistic implication is based on deduction. For the intuitionist, if $A$ then $B$ literally means from the assumption A one can deduce $B$.

\footnotetext{
${ }^{11}$ The axiom of choice states that for every collection of non-empty sets, there is a set containing exactly one element from each of the sets from the collection.
} 
Understanding implication intuitionisticaly results in the law of the excluded middle being rejected. In the natural deduction system for intuitionistic logic NJ (Gentzen 1935), the implication is characterized, just like all the other connectives, by a pair of rules: the introduction rule and the elimination rule. The introduction rule states that $\mathrm{A} \rightarrow \mathrm{B}$ can be inferred if from $n$ occurences of the assumption $A(n \geq 0)$, one can deduce B. If such a conclusion is achieved, $\mathrm{A}$ is no longer considered to be relevant and can be discharged. The elimination rule is just the modus ponens. These rules describe the deductive behavior of the intuitionistic implication. To obtain the classical conditional, and to progress from NJ to NK (the natural deduction system for classical propositional logic defined in: (Gentzen 1935)) one has to stipulate in addition the law of the excluded middle as an axiom, which cannot be derived in NJ. Equivalently, to NJ one can add the Pierce's rule from which, together with NJ, the law of the excluded middle follows. Pierce's rule allows one to infer $\mathrm{A}$ from the assumption $\mathrm{A} \rightarrow \mathrm{B}$, and discharge the assumption, if one has deduced $\mathrm{A}$ from $\mathrm{A} \rightarrow \mathrm{B}$. This rule cannot be justified on the basis of the introduction and elimination rules for the implication alone, and bears an additional assumption that the implication is material or truthfunctional.

Why is intuitionistic understanding of the implication intensional? For two reasons. In classical logic, the meaning of the implication is reduced to a truth function. In intuitionistic logic, the meaning of the implication is given by the rules of deduction (modus ponens and the rule of implication introduction). According to this account, logical words do not obtain their meaning by labeling objects but their meaning is built upon the rules of their use. As we have already remarked, this is a semantical standpoint inspired by Wittgenstein and fully developed later in proof-theoretic semantics.

There is yet another aspect in which intuitionistic implication made an intensional breakthrough. While classical (material) implication is related to the (semantic) consequence relation, intuitionistic implication is related to deduction. This distinction is very often ignored. A proposition $\mathrm{A}$ is a consequence of a collection of propositions in $\Gamma$ if $\mathrm{A}$ is true when each of the propositions in $\Gamma$ is true and this is written as $\Gamma$ F 
A. In other words, $\Gamma$ F A holds iff for every valuation of the propositional letters in $\mathrm{A}$ and $\Gamma, \mathrm{A}$ is true or there is a proposition in $\Gamma$ that is false. When $\Gamma$ is a singleton containing only a proposition $\mathrm{B}$, the consequence relation then amounts to the material implication, that is $\Gamma=\mathrm{A}$ iff for every valuation $v, v(\mathrm{~B} \rightarrow \mathrm{A})=1$. In a more general case, when there is a finite number $\mathrm{n}$ of propositions in $\Gamma$, these propositions can be combined into an $\mathrm{n}$-ary conjunction. But, the consequence relation again amounts to the relation between an antecedent and a consequence of the material implication; it is just that the antecedent is now a conjunction. (Došen 1997, 291)

The main difference between deduction and consequence relation is that there is only one way in which a proposition $\mathrm{A}$ is a (semantic) consequence of $\Gamma$, either $\Gamma=\mathrm{A}$ holds or it does not hold (Since the relation is understood extensionally, as a set of ordered pairs.) On the other hand, there can be multiple different ways in which A can be deduced from $\Gamma$. Consider the following example. Let $\Gamma$ be a collection of propositions: $\mathrm{C} \rightarrow \mathrm{A}, \mathrm{B} \wedge \mathrm{A}, \mathrm{D}, \mathrm{C}$. By using these propositions as hypothesis we can deduce $\mathrm{A}$ in two different ways. We can obtain A from $\mathrm{B} \wedge \mathrm{A}$, by using the second rule for conjunction elimination which gives us the second conjunct. On the other hand, A can also be obtained by using $\mathrm{C} \rightarrow \mathrm{A}$ and $\mathrm{C}$ as hypothesis and applying modus ponens. Obviously, two deductions are different because they have different premises. However, one can even differentiate between deductions with the same premises and the same conclusion. For instance, A can be deduced from $((\mathrm{C} \rightarrow \mathrm{A}) \wedge$ C) $\wedge \mathrm{A}$ in two ways. The second rule for conjunction elimination directly obtains the result. But $\mathrm{A}$ can also be obtained by inferring the first conjunct $\mathrm{C} \rightarrow \mathrm{A} \wedge \mathrm{C}$, and then, after eliminating the conjunction twice, applying modus ponens. Thus, we have two ways of deriving A which represent two distinct deductions correspondingly.

Deductions are not ordered pairs (of sets of premises and conclusions), they are ways of deriving a conclusion from the premises. When one realizes that, one understands deduction intensionally. This has not been the default approach to deductions, however. This is the approach taken in general proof theory. Proof theory is a branch of logic whose object of study are proofs. (In the rest of the text we will use the 
terms proof and deduction interchangeably.) The main concern of general proof theory is to investigate proofs through proof identity criteria. Essentially, two kinds of identity criteria have been developed. The first one, which is far more well-known, stems from Prawitz and it is based on the notion of normal form. Intuitively, a proof in normal form is a proof without redundant steps. Inspired by (Gentzen 1935) who defined the notion of a normal proof in the sequent calculus, in (Prawitz 1965) Prawitz defines the procedure for reducing a natural deduction proof to its normal form. The idea is that by applying the procedure one does not change the proof essentially. So, the proposal is that two deductions are equal if and only if they normalize in the same manner, that is - their formal representations can be reduced to the same normal form. The second kind of identity criteria, first formulated by Lambek, are based on the notion of proof generality (see: Lambek 1972,65). Simply put, generalizing a proof amounts to understanding it in terms of instances of rule applications. According to this criteria, two proofs are said to be equal if and only if they are of the same generality - that is - if the generalization of the first one leads to the generalization of the second (for more details see: Došen \& Petrić 2004).

The idea common to both approaches to proof identity is to find mathematical representations of proofs and to define an equivalence relation on the representations such that a proof can be seen as an equivalence class of its representations (inside a given framework). All the representations that belong to the same equivalence class as a representation $d$ are representations of the same proof as $d$. An inspiration for such an approach one owes to (Frege 1884, §64) where Frege defines the notion of a direction as an equivalence class of parallel lines.

How are proof representations constructed? In general proof theory one uses the categorical framework. ${ }^{12}$ Proof representations are seen as arrows inside a category and proofs are understood as equivalence classes of their arrow representations. Two representations are considered equivalent - they represent the same proof if the appropriate arrows are

\footnotetext{
${ }^{12}$ For an introductory into category theory, the reader is recommended to consult (Mac Lane 1998)
} 
equal in a suitable category. The categories suited for intuitionistic logic are bicartesian closed categories. Prawitz's normalization criteria for the identity of proofs of intuitionistic logic exactly correspond to the equality of arrows in bicartesian closed categories.

The proof identity criteria studied in general proof theory are intensional. They do not reduce proofs to consequence relations; they also do not reduce them to syntax, since these criteria yield equalities between distinct syntactical objects. And in addition, both kinds of criteria turn out to be mathematically interesting on their own. For instance, the normalization criteria form the mathematical structure of the bicartesian closed categories. All of the aforesaid points to the fact that the sense of the notion of proof is captured in general proof theory. It is not reducible to mere syntax, or to the consequence relation. It is something over and above it.

So far, we have only discussed the identity criteria that are based on normal form, and haven't said much about the ones that are based on generalization. Due to the aim and the volume of this exposition, we have to leave the discussion on generalization for elsewhere. It is noteworthy though, to mention that while the normalization criteria work quite well for intuitionistic proofs, the generalization criteria are more suited for classical proofs (See: Došen \& Petrić 2004).

Unlike set theory, category theory is more suitable to intensional characterizations, because arrows are not reduced to ordered pairs of sources and targets. For an arrow $f: A \rightarrow B$, the source of $f$ is the object $A$ and the target is the object $B$. Different arrows represent different ways for getting from the source to the target. In a category, the operations on arrows are defined not in a standard set - theoretic manner, from the inside, but by the laws that govern the behavior of these operations, that is, from the outside. Let us try to explain this a little bit. Consider the notion of the Cartesian product. In set theory the Cartesian product is defined as a two-place operation on sets. The result of applying this operation, $\mathrm{A} \times \mathrm{B}$ is again a set whose members are ordered pairs $(a, b)$, such that $a$ is a member of $\mathrm{A}$ and $b$ a member of $\mathrm{B}$. We have thus characterized the Cartesian product from the inside, by enlisting its members. 
In category theory, the notion of the Cartesian product is characterized from the outside, using the notion of categories with finite products or Cartesian categories. The chief idea of this kind of analysis is that one does not care what is inside $\mathrm{A} \times \mathrm{B}$, we do not even know if $\mathrm{A}$ and $\mathrm{B}$ are sets. In general, they can be anything, they are just specified as objects. We characterize A $\times$ B so to speak, in terms of its behavior. (An idea of an outside characterization we owe to: Došen 2017).

A Cartesian category is a category with binary products and a terminal object $\mathrm{T}$ (which stands for an empty product). Now, if a category has a (binary) product $\mathrm{A} \times \mathrm{B}$, it comes equipped with special arrows: $p_{A, B}^{l}: A \times B \rightarrow A$, which represents the first projection, $p_{A, B}^{2}: A \times B \rightarrow A$ which represents the second projection, and the operation on arrows called pairing, which from arrows $f: C \rightarrow A$ and $g: C \rightarrow B$ constructs an arrow $\langle f, g\rangle: C \rightarrow A \times B$. The meaning of the (binary) product is characterized by the equalities that govern the behavior of the projections and the pairing. An example is $p_{A, B}^{l}\langle\langle f, g\rangle=f$ (where * stands for the composition of arrows, which is defined as a partial associative binary operation on arrows) ${ }^{13}$. This equality states that applying the projection after the pairing is somewhat superficial, since it results in an arrow that is identical to $f$.

Interestingly, the equality exactly corresponds to a proof equality of Prawitz, that is the result of a normalization. Imagine objects being propositions, the product being a conjunction, arrows being deductions, the first projection standing for the first rule of conjunction elimination, and the pairing as conjunction introduction. This equality states that every conjunction introduction followed by an elimination can be removed as a redundant proof step.

The difference between inside and outside characterization is maybe easier to understand if compared to a distinction between direct and implicit definitions. The notion of implicit definition dates to Hilbert and Poincare. They realized that the axioms of Euclidean geometry can

\footnotetext{
${ }^{13}$ Every two arrows $f, g$ can be composed into $g^{*} f$, provided that the source of $g$ is the same as the target of $f$. In other words, if one has $f: A \rightarrow B$ and $g: B \rightarrow C$, then one obtains $g^{*} f: \mathrm{A} \rightarrow \mathrm{C}$.
} 
be understood as definitions of notions appearing in them (Poincare 1902) (Hilbert 1899). The idea of this kind of definition is to describe the meaning of a concept by stipulating some axioms that hold true of it, or to put it differently, that determine its use in deductions. An implicit definition deviates from the traditional, Arisotlenean one in various respects. Firstly, it does not have a standard form of a definition $s=t$, where $\mathrm{s}$ is the definiens and $\mathrm{t}$ the definiendum. Secondly it is nonreductive, because a term is defined with regard to axioms that again must contain this term.

Unlike set theoretical characterizations of notions, which are reductive, categorial characterizations may appear circular, just like implicit definitions. Category theory is sometimes held to represent alternative foundations for mathematics, but the truth is that category theory does not replace set theory. Category theory provides a good characterization or clarification of important mathematical notions, such as for instance the notion of the Cartesian product, the notion of function and many more. However, one cannot say that in the traditional sense of the word category theory defines the notion of function, since the very definition of a category presupposes the notion of function as given. (see: Došen 2017) In that manner categorial characterizations are more like implicit definitions. They are sometimes circular and not necessarily reductive. Yet, this shouldn't be regarded as a bad thing. On the contrary. Just like the abstraction of the intensional (components) in set theory should not be thought of as a defect of an analysis, but as a useful tool, non-reductiveness should be looked upon as a purposeful feature of the framework that enables us to comprehend and describe intensionality. At the end of the day, maybe intensional explanations are just not meant to be reductive.

\section{CONCLUSION}

Characterizing notions from the outside, by studying the rules that govern their behavior, is a common feature of the intensional approaches we have here presented. Is maybe to some extent even a feature of this exposition (thereby making it slightly self-referential). In 
proof theoretic semantics we do not define the meanings of the connectives by seeing them as labels for set-theoretic entities but we understand them functionally - by the rules they obey in deduction. We can call this approach a functional approach to meaning. A functional approach to meaning is what is common to general (categorial) proof theory, proof theoretic semantic, intuitionistic logic and we believe it is a very important aspect of the intensional approach in general.

Granting rules a special connection to meaning is what is common to both the Wittgensteinean account of sense we have here proposed and Frege's. By taking the extensional approach we conform to focus only on the results of applying these rules and to forget about the rules themselves. While there is nothing generally wrong with this position, why should one be prohibited to also investigate the rules in themselves and the structures formed by their application? We have tried to depict the intensional approaches presented here as successfully fulfilling this aim.

\section{REFERENCES}

Augustine, of Hippo, Saint, (354-430) The Confessions of Saint Augustine, Pusey, E. B., Valenti, A. (eds.), Mount Vernon: Peter Pauper Press.

Berarducci, A. \& Dezani-Ciancaglini, M. (1999) "Infinite A-calculus and types", Theoretical Computer Science, Vol. 212, pp. 29-75.

Church, A. (1951) "A Formulation of the Logic of Sense and Denotation", in Structure, Method, and Meaning; Essays in honor of Henry M. Sheffer, Henle, P., Kallen, H. (eds.), Liberal Arts Press, NY., USA, pp. 3-24.

Church, A. (1973) "Outline of a Revised Formulation of the Logic of Sense and Denotation (Part I)", Noûs, Vol. 7, No. 1, pp. 24-33.

Church, A. (1974) "Outline of a Revised Formulation of the Logic of Sense and Denotation (Part II)", Noûs, Vol. 8, No. 2, pp. 135-156.

Church, A. (1993) "A Revised Formulation of the Logic of Sense and Denotation. Alternative (1)", Noûs, Vol. 27, No. 2, pp. 141-157.

Crocco, G., Van Atten, M., Cantu, P., Engelen, E. M. (eds.) (2017) Kurt Gödel Maxims and Philosophical Remarks Volume X.

Davidson, D. (1967) “Truth and Meaning”, Synthese Vol. 17, pp. 304-323. 
Devlin, K. (2003) "The forgotten revolution", available online: (https://www.maa.org/external_archive/devlin/devlin_03_03.html) (accessed on September $1^{\text {st }}, 2020$ ).

Došen, K. (1989) "Logical constants as punctuation marks", Notre Dame Journal of Formal Logic, Vol. 30, pp. 362-381.

Došen, K. (1997) "Logical consequence: A turn in style", Logic and Scientific Methods, Chiara, M. et al. (eds.), pp. 289-311.

Došen, K. and Petrić, Z. (2004) "Identity of proofs based on Normalization and Generality“, available online: (https://arxiv.org/pdf/math/0208094.pdf) (accessed on September $1^{\text {st }}, 2020$ ).

Došen, K. (2001) "Abstraction and application in adjunction" available online: (arXiv:math/0111061) (accessed on September $\left.1^{\text {st }}, 2020\right)$.

Došen, K. (2013) Основна логика, available online: (http://www.mi.sanu.ac.rs/ kosta/Osnovna\%20logika.pdf) (accessed on September $\left.1^{\text {st }}, 2020\right)$.

Došen, K. (2017) "Should the explicans be simpler than the explicandum?", Proof Theory as Mathesis Universalis, Loveno di Menaggio (Como), abstract available online: http://www.mi.sanu.ac.rs/ kosta/K\% 20Dosen_Como.pdf (accessed on September $1^{\text {st }}, 2020$ ).

Dummett, M. (1978) Truth and Other Enigmas, Cambridge, MA: Harvard University Press.

Dummett, M. (1991) The Logical Basis of Metaphysics, London: Duckworth.

Frege, G. (1879) Begriffsschrift, a Formula Language, Modeled upon that of Arithmetic, for Pure Thought. In From Frege to Gödel, edited by Jean van Heijenoort. Cambridge, MA: Harvard University Press, 1967. Originally published as Begriffsschrift, eine der arithmetischen nachgebildete Formelsprache des reinen Denkens (Halle: L. Nebert).

Frege, G. (1884) Die Grundlagen der Arithmetik: eine logisch mathematische Untersuchung über den Begriff der Zahl (English translation: The basic laws of arithmetic: The exposition of the system, Furth, M. (ed.), Berkeley, CA: University of California Press, 1982).

Frege, G. (1891) "Funktion und Begriff”, in: Funktion, Begriff, Bedeutung: Fünf logische Studien, Patzig, G. (ed.), Göttingen: Vandenhoeck \& Ruprecht, 1962.

Frege, G. (1948) "Sense and reference", The Philosophical Review Vol. 57, No. 3, pp. 209-230.

Gentzen, G. (1935) "Untersuchungen über das logische Schliessen", Matematische Zeitschrift Vol. 39, pp. 176-210, (English translation: "Investigations into logical deduction", The Collected Papers of 
Gerhard Gentzen, Scabo, M. (ed.), Amsterdam: North-Holland Publishing Company, pp. 68-132, 1969).

Gödel, K. (1944), "Russell's Mathematical Logic", in Collected Works, II: Publications 1938-1974, S. Feferman, J. W. Dawson, S. C. Kleene, G. H. Moore, R. M. Solovay, Jean van Heijenoort (eds.), Oxford:Oxford University Press, pp. 119-141

Grice, H. P. (1989) Studies in the way of words, Cambridge, MA: Harvard University Press.

Hamkins, J. D. \& Lewis, A. (1998) "Infinite time Turing machines", available online: (arXiv:math/9808093v1) (accessed on September $\left.1^{\text {st }}, 2020\right)$.

Hilbert, D. (1899) Grundlagen der Geometrie. Tuebner, (English translation:The Foundations of Geometry, Chicago, IL: The Open Court Publishing Company, La Salle, 1950).

Kostić, J. "Gödel on the theory of concepts", (manuscript in preparation).

Kostić, J. \& Maksimović, K. (2020) "Growing into deduction", Theoria, Vol. 63, pp. 87-106.

Kostić, J., Maksimović, K., Milošević, S. "Is natural deduction natural", (manuscript in preparation).

Lambek, J. (1972) "Deductive systems and categories III: Cartesian closed categories, intuitionist propositional calculus, and combinatory logic", in: Toposes, Algebraic Geometry and Logic (Lecture Notes in Mathematic 274), Lawvere F.W. (ed.), Berlin: Springer, pp. 57-82.

Mac Lane, S. (1998) Categories for the Working Mathematician, second edition, Berlin: Springer.

Maksimović, K. (2016) "Uses of the Language of Mathematics", Theoria, Vol. 59 , No. 1, pp. 26-41.

Poincare, H. (1902) La Science et L'Hypoth 'ese, Paris: Flammarion, English translation: Science and Hypothesis, The Value of Science, Science and Method., Halstead, G. B. (ed.), Lanham, MD: University Press of America, 1982.

Prawitz, D. (1965) Natural Deduction: A Proof-Theoretical Study, Stockholm: Almqvist \& Wiksell.

Prawitz, D. (1971). "Ideas and Results in Proof Theory", Proceedings of the Second Scandinavian Logic Symposium (Oslo 1970), Jens E. Fenstad (ed.), Amsterdam: North-Holland, pp. 235-308.

Schroeder-Heister, P. (2012) "Proof-theoretic semantics", Zalta, E.N. (ed.), The Stanford Encyclopedia of Philosophy, available online: https://plato.stanford.edu/entries/proof-theoretic-semantics/ (accessed on September $1^{\text {st }}, 2020$ ). 
Schroeder-Heister, P. (2013) "Definitional Reflection and Basic Logic", Annals of Pure and Applied Logic, Vol. 164, No. 4, pp. 491-501.

Schroeder-Heister, P. (2015) "Proof-theoretic validity based on elimination rules". In: Haeusler, E. H., de Campos Sanz, W. and Lopes B., (eds.), Why is this a Proof? Festschrift for Luiz Carlos Pereira. London: College Publications, pp. 159-176.

Wang, H. (1996) A Logical Journey: from Gödel to Philosophy, Cambridge: MIT Press.

Wittgenstein, L. (1958) Philosophical Investigations, Oxford: Basil Blackwell.

\author{
KATARINA MAKSIMOVIĆ \\ Univerzitet u Beogradu, Filozofski fakultet
}

\title{
ASPEKTI INTENZIONALNOSTI
}

Sažetak: Cilj rada je da čitaoca uvede u razliku između onoga intenzionalnog i onoga ekstenzionalnog kao distinkciju između različitih pristupa značenju. Tvrdićemo da, uprkos opštem uverenju, intenzionalni aspekat matematičkih pojmova može biti, pa i da zapravo jeste uspešno opisan u matematici. Jedan od onih koji su za nas naročito interesantni jeste pojam dedukcije onako kako je prikazan u opštoj teoriji dokaza. Naša razmatranja za rezultat imaju odbranu a) važnosti semantičkog pristupa zasnovanog na pravilima $i$ b) pozicija prema kojima neredukcionistička i donekle cirkularna objašnjenja igraju suštinsku ulogu u opisivanju intenzionalnosti u matematici.

Ključne reči: intenzionalna logika, intenzionalna definicija, dokazno-teorijska semantika, teorija dokaza, implicitna definicija

Primljeno: 1.9.2020.

Prihvaćeno: 11.11.2020. 